Citation: Balzter, H., Skinner, L., Luckman, A., and Brooke, R. (2003): Estimation of tree growth in a conifer plantation over nineteen years from multi-satellite L-band SAR. Remote Sensing of Environment 84, 184-191.

\title{
Estimation of tree growth in a conifer plantation over nineteen years from multi-satellite L-band SAR
}

\author{
Authors: Balzter ${ }^{1}$, H., Skinner ${ }^{2}$, L., Luckman $^{2}$, A., and Brooke, R. ${ }^{3}$
}

\section{Address for correspondence}

Heiko Balzter

${ }^{1}$ Centre for Ecology and Hydrology Monks Wood

Section for Earth Observation

Abbots Ripton

Huntingdon, Cambridgeshire, PE28 2LS

UK

phone $+44(0) 1487-772400$

direct dial +44 (0)1487 772471

fax +44 (0)1487-77 3277

email: hbal@ceh.ac.uk

${ }^{2}$ Department of Geography, University of Wales, Swansea, UK

$\left.\begin{array}{ll}\text { email L.Skinner } \\ & \text { A.Luckman }\end{array}\right\} @$ swan.ac.uk

${ }^{3}$ Forest Enterprise, East Anglia Forest District, UK

email Richard.Brooke@forestry.gov.uk

\begin{abstract}
The general capability of Synthetic Aperture Radar (SAR) for monitoring forest ecosystems is well documented. However, the majority of SAR studies of forest dynamics use only imagery acquired by one SAR system and are thus limited to the lifecycle of a particular satellite. The synergistic analysis of SAR data from one of the earliest spaceborne SAR missions, the SEASAT mission, with the Japanese JERS-1 satellite-borne SAR is presented. Biophysical parameters frequently retrieved from SAR are tree biomass using backscatter and tree height from the interferometric phase. One potential application that has not been thoroughly examined is mapping of incremental tree growth from SAR backscatter changes. Tree growth measures biomass changes over time, and is correlated to the amount of carbon sequestered by a the trees. This paper examines the retrieval of tree growth from multitemporal spaceborne L-band SAR. A SEASAT SAR image from 1978 and a JERS-1 SAR image from 1997 over Thetford forest, UK, are used to retrieve tree growth of Corsican Pine stands.

Incremental growth was estimated from the changes in backscatter coefficient, and compared to the expected tree growth from general yield class models used by the UK Forestry Commission. The accuracy of the retrieval algorithm depends on the minimum forest stand size included in the analysis. For managed forest plantations, multitemporal L-band SAR has some potential for detecting incremental biomass to support sustainable forest management.
\end{abstract}

\section{Keywords}

Corsican Pine, Thetford forest, biomass, backscatter, Synthetic Aperture Radar, temperate forest, Pinus nigra var maritima 


\section{INTRODUCTION}

Forest biomass is a biophysical parameter required by many scientific disciplines. Maps of forest biomass can be used to refine model predictions of the global carbon cycle (Plummer 2000). The spatial distribution of forest biomass and its heterogeneity can be quantified by landscape indices and are related to biodiversity of certain insect species (Ferris et al. 2000) and other groups of species currently discussed as biodiversity indicators. Particularly, detecting changes in forest biomass is of interest to policy makers, international agencies and forest managers. Incremental tree growth is also a key variable for estimating net primary productivity, and ultimately carbon fluxes. In the context of the implementation of the UN Framework Convention on Climate Change, the development of a monitoring capability of carbon sequestration in forest ecosystems has become a high research priority (Dawson et al. 2000).

SAR is the only sensor type, which images volumes of vegetation rather than reflectance from the surface of the canopy. The transmitted microwave radiation penetrates the vegetation canopy to a wavelength and polarisation-dependent depth. Within the imaged volume, the radiation is scattered by primary scattering elements with sharp boundaries in dielectric constant, like branches and leaves. The difference in dielectric constant is mainly due to the water content of the vegetation. The imaging process makes SAR suitable for mapping parameters related to forest biomass, like stem volume (Pulliainen et al. 1996, Hyyppä et al. 1997, Israelsson et al. 1997, Baker and Balzter 1999, Fransson and Israelsson 1999, Kurvonen et al. 1999), total growing stock (Schmullius and Rosenqvist 1997, Balzter et al. 2000, Balzter et al. submitted), LAI (Imhoff et al. 1997), or above-ground net primary productivity (Bergen et al. 1998).

For the UK Forestry Commission top height of a forest stand is a crucial parameter. Top height is defined as the average height of a number of trees of largest breast height diameter in a 0.01 ha sample plot (Forestry Commission 1981). It is used together with the yield class, diameter at breast height (dbh) and basal area to estimate the cumulative volume production of a stand.

Radar backscatter typically increases in a non-linear way with forest biomass. The function depends mainly on wavelength, polarization, forest type, scatterer geometry and moisture conditions. A long wavelength like $23 \mathrm{~cm}$ (L-band) is required to penetrate the upper canopy layer and interact with branches and stems.

The main limitation in SAR remote sensing of forests is the saturation of the signal at a certain biomass level. The sensitivity of L-band SAR to forest biomass can be between $30 \mathrm{t} / \mathrm{ha}$ and 250 t/ha (Baker and Balzter 1999, Baker and Luckman 1999). Given the saturation of the signal, L-band SAR could potentially map the biomass density of $8 \%$ of the world's phytomass (Imhoff 1995). The limited life cycles of the two satellites carrying L-band SAR systems, SEASAT and JERS-1, have restricted their capabilities for change detection over longer time scales. However, future spaceborne missions like ALOS, LightSAR or TerraSAR will enable the production of change maps of forest biomass from long time series of multiplatform L-band SAR data. This paper investigates the use of repeated SAR observations from SEASAT and JERS-1 for estimating top height increments of Corsican Pine stands over nineteen years, the longest period ever studied. It is the first study known to the authors attempting to retrieve incremental tree growth directly from SAR.

\section{METHODS AND STUDY SITE}

Thetford forest is a forest plantation in East Anglia, UK, at 52 $30^{\prime} \mathrm{N}, 0^{\circ} 30^{\prime} \mathrm{E}$ (Randall and Dymond 1996). It was planted by the Forestry Commission in the 1920's and 30's. The height above mean sea level is around 15-30 m. The Breckland Environmentally Sensitive Area extends over $940 \mathrm{~km}^{2}$, of which $7.4 \%$ is heath land, $25 \%$ mostly coniferous plantation and the remaining 65\% arable farmland and development (Barkham 1996). Most of Thetford forest is 
managed by clear fell rotation, but small parts are mixed-age stands. Plantations are $85 \%$ conifers, $9 \%$ mixed woods and 6\% broadleaves. Main species (source: Forestry Commission, $1990)$ are Corsican Pine (54\%) and Scots Pine (31\%) with Beech (4\%), Oak (3\%), Douglas Fir $(2 \%)$ and Birch, Poplar and Larch (1\% each).

Table 1 shows the acquisition details of the SAR imagery used here. The SEASAT scene was cross-calibrated with an empirical calibration constant of $2.4 \mathrm{~dB}$, so that the saturated signal for high-biomass forest matches the JERS-1 signal. The UK Forestry Commission provided a GIS database with standwise information on tree species, planting year and yield class $\left(\mathrm{m}^{3} \cdot \mathrm{ha}\right.$ ${ }^{1} \cdot \mathrm{a}^{-1}$ ). Mean top height $h_{F C}$ of each stand was calculated based on stand age and published general yield class curves for Corsican Pine (Forestry Commission 1981) using a fourth-order polynomial. Expected incremental growth $\Delta h_{F C}$ was estimated by subtracting two $h_{F C}$ values derived from the yield class models for both satellite image acquisition dates. For stands that were harvested by clearcutting between 1978 and 1997, $\Delta h_{F C}$ was estimated using the replanting year.

The radar signal depends on geometric and dielectric properties of the scatterers in the imaged volume element. The scattering mechanisms at L-band in a forest canopy are mainly volume scattering in the canopy, double-bounce scattering between trunks and the ground, and surface scattering from the forest floor. Accordingly, the predominant scatterers at L-band are branches, stems and the soil. Top height of a forest stand is correlated to the number density and size of branches and stems, so a functional relationship is to be expected. A simulation study using a cylinder model for the vegetation canopy and the radiative transfer model RT2 (Saich 1993) confirmed the expected physical relationship. The vegetation layer was described as a volume containing stems, branches and needles varying with canopy height (Figure 1). Figure 2 shows the total L-HH backscatter at $35^{\circ}$ incidence angle modelled by RT2 for increasing canopy height. Also shown are the backscatter components contributed by the ground, the vegetation layer and the first-order layer-ground interactions. With increasing canopy height the backscatter comes more from layer-ground interactions and less from direct layer scattering.

The SAR images were multilooked and coregistered to the Forestry Commission database at $12.5 \mathrm{~m}$ pixel spacing using ground control points. Polygon erosion by one pixel at the edges of the polygons was performed to reduce the impact of coregistration errors on the statistical analysis.

\section{Indirect method}

The first approach to derive growth is to estimate top height from the SEASAT and from the JERS-1 image independently, and to calculate the height difference (indirect method). Exponential models of $\sigma^{0}$ (Luckman et al. 1998) were used to retrieve top height of Corsican Pine stands from both images:

$$
\sigma^{0}=a-e^{-h_{F C}+c_{-}^{-}}
$$

where $\sigma^{0}$ is the backscatter coefficient $[\mathrm{dB}]$ and $h_{F C}$ is the mean top height per stand [m] from the Forestry Commission data. The parameters $a, b$ and $c$ were estimated with a non-linear least squares algorithm.

The model was inverted to retrieve $h_{1997}$ and $h_{1978} . \Delta h_{\text {ind }}$ is the difference between $h_{1997}$ and $h_{1978 \text {. }}$

\section{Direct method}

The second approach (direct method) estimates tree growth from temporal backscatter change directly. This method avoids the error sources in the top height - backscatter models. Its quality relies on the correlation of tree growth with the temporal changes in the number density and size distribution of scatterers relevant at L-band. 
The direct retrieval algorithm fits an empirical model to the function of the backscatter coefficient change $\Delta \sigma^{0}[\mathrm{~dB}]$ depending on $\Delta h_{F C}$. A logarithmic, a linear and a square root model were compared:
(a) $\Delta \sigma^{0}=a+b \cdot \log \Delta h$
(b) $\Delta \sigma^{0}=a+b \cdot \Delta h$
(c) $\Delta \sigma^{0}=a+b \cdot \sqrt{\Delta h}$

The parameters $a$ and $b$ were fitted using a least-squares algorithm. The models were inverted to retrieve incremental growth $\Delta h_{d i r}$.

\section{RESULTS}

The colour-composite in Figure 3 shows the 1978 SEASAT backscatter coefficient as blue, the 1997 JERS-1 backscatter coefficient as green and temporal backscatter change as red. Regrowth appears yellow (low $\sigma_{1978}^{0}$; high $\sigma_{1997}^{0}$; and medium $\Delta \sigma^{0}$ ), stands that were cut between the two acquisition dates are dark blue (high $\sigma_{1978}^{0}$; low $\sigma_{1997}^{0}$; and medium $\Delta \sigma^{0}$ ), undisturbed forest stands are light blue (high $\sigma_{1978}^{0}$; high $\sigma_{1997}^{0}$; and low $\Delta \sigma^{0}$ ) and agricultural fields are brown (low $\sigma_{1978}^{0}$; low $\sigma_{1997}^{0}$; and high $\Delta \sigma^{0}$ ). The town of Thetford is in the lower right corner of the image. The homogeneity of the stands in this managed plantation is clearly visible in the image despite the presence of speckle.

The relationships between $\sigma^{0}$ and top height of Corsican Pine stands for the two acquisitions are shown in Figure 4. The curve for SEASAT is noisier than for JERS-1. The saturated backscatter signal for mature forest stands is around $-6 \mathrm{~dB}$ (Figure 4) and is in agreement with findings by other studies (Ranson and Sun 1997, Baker and Luckman 1999).

\section{Indirect method}

From the models shown in Figure 4 top height was estimated for both image acquisition dates by model inversion, and growth was calculated by subtraction of heights. Inverting this type of model causes problems with the backscatter values above the saturation limit, for which height is not defined. The rmse of top height estimates [m] from individual SAR acquisitions was $5.9 \mathrm{~m}$ for the SEASAT and $6.0 \mathrm{~m}$ for the JERS-1 image. For tree growth the rmse was $8.2 \mathrm{~m}$. This resulting rmse of growth is obtained from a combination of the errors of the two individual models according to the error propagation equation:

$$
r m s e_{d i r}=\sqrt{r m s e_{1}^{2}+r m s e_{2}^{2}}
$$

\section{Direct method}

A plot of backscatter change $[\mathrm{dB}]$ between 1978 and 1997 and top height is shown in Figure 5. The shape of the point cloud shows a slightly non-linear trend. To take this into account the square root and log model were fitted to the data in addition to the linear model (Eq. 2a, $\mathrm{b}$ and c). All fitted models are shown in Figure 5. The square root and the log model saturate at a level beyond the observed tree growth range, and their saturation levels are indicated by horizontal lines. The curves show only minor differences, indicating that the deviation from linearity is small. The rmse of $\Delta h_{d i r}$ obtained from model inversion is $3.1 \mathrm{~m}$ for the log model (including only stands with mean $\Delta \sigma^{0}<2 \mathrm{~dB}$ ), $3.4 \mathrm{~m}$ for the linear model (all stands) and 4.2 $\mathrm{m}$ for the square root model (all stands). The saturating behaviour of the log and square root model implies that their rmse increases strongly for high values of $\Delta \sigma^{0}$. Because of the limitations of these models, in the following sections the linear model is used unless otherwise stated. 


\section{Comparison}

Figure 6 shows scatterplots of the estimated incremental growth by the indirect and direct method and the expected growth from the Forestry Commission database. The indirect method does give a bias towards underestimation of growth and shows large scatter around the trend. The direct method gives much better results (Figure 6) as quantified by the lower rmse. It is unbiased and shows a better goodness of fit.

The impact of natural variation and sample size on the precision of the growth estimates by the direct method was analysed by successively excluding small forest stands below a certain stand area from the analysis. The results of this experiment are shown in Figure 7. Increasing the minimal stand size from 0 to 2.1 ha reduces the rmse of all three models by approximately one metre.

Figure 8 summarizes the different errors in the growth estimates. The stand area has a significant impact on the rmse of the direct but not of the indirect method.

The map of tree growth at Thetford forest obtained from the direct method (linear model) is presented in Figure 9. The SAR-derived estimates were linked to the Forestry Commission GIS. This data product can easily be used in forest management to assess the likely tree growth in particular stands. Even if the rmse of the estimates is considered too high to draw quantitative conclusions about individual stands, the data product can serve as additional guidance on prioritising stands for more detailed assessment using forest mensuration techniques.

\section{DISCUSSION AND CONCLUSIONS}

In managed coniferous plantations mean top height, diameter at breast height, stand age and total growing stock are highly correlated with each other. Spaceborne L-band SAR is capable of repeated all-weather, day and night mapping of such plantations. A severe limitation in retrieving biomass-related biophysical parameters like mean top height from L-band backscatter is the saturation of the signal at relatively low biomass, and the high uncertainty resulting from error propagation.

The use of multiple-platform L-band SAR to quantify changes in forest ecosystems has not been investigated before. Although SEASAT was not designed as a terrestrial mission, it proved useful in conjuction with JERS-1 in the presented study. Despite the slightly different sensor characteristics and viewing geometries the joint use of SEASAT and JERS-1 imagery has made it possible to quantitatively estimate incremental tree growth at Thetford forest. The time interval between the two image acquisitions of 19 years coincides with the stand age of Corsican Pine at Thetford forest for which the radar backscatter signal saturates. This is the maximum temporal difference tolerable for change detection with the direct method presented in this paper.

The error propagation using the indirect method estimating biophysical variables separately from the two images and subtraction the two, proved to have a serious effect on the precision and accuracy of the tree growth estimate. The variation of individual tree height estimates introduced by natural variables like vegetation structure, slope, soil roughness, and others caused a high uncertainty in the tree growth estimate. The direct method avoids this error propagation and gave results of acceptable quality.

The practical use of the presented method has been shown by linking the tree growth data product back to the Forestry Commission database. With future sensors an automated implementation of data downlink, pre-processing, parameter retrieval and linking to the database could provide a near-real-time update of the forest management GIS. Multitemporal estimates also provide the possibility of averaging over time, which would further reduce the impact of natural variability and improve precision and accuracy.

The algorithm has so far only been verified at a homogeneous coniferous plantation, and the well known biophysical properties and little natural variability enables the quantitative 
estimation of tree growth. In more complex forests, canopy structure will play an important role in determining the signal, and has to be taken into account when estimating incremental growth. However, for regrowth after disturbances like clearcuts or fire, forest stands often are relatively homogeneous, and the algorithm could be tested in other biomes without alterations.

The incomplete coverage of global forest biomes by SEASAT limits its use as a historic baseline for change detection. Future missions like ALOS, TerraSAR or LightSAR will add invaluable data to the existing previously acquired L-band SAR archives.

\section{ACKNOWLEDGEMENTS}

This work was funded by the Earth Observation Programme of the Natural Environment Research Council, UK. JERS-1 data are courtesy of NASDA/MITI. (C) RT2 by BAE Systems Advanced Technology Centre, Chelmsford, UK. Paul Saich (UCL) provided valuable advice on using RT2. 


\section{REFERENCES}

Baker, J. R., and Balzter, H., 1999, Observations of the wintertime boreal environment using radar remote sensing techniques, Institute of Terrestrial Ecology Monks Wood).

Baker, J. R., and Luckman, A. J., 1999, Microwave observations of boreal forests in the NOPEX area of Sweden and a comparison with observations of a temperate plantation in the UK. Journal of Agricultural and Forest Meteorology, 98, 389-416.

Balzter, H., Baker, J. R., Hallikainen, N., and Tomppo, E., 2000, Mapping of a Finnish boreal forest under changing snow conditions with airborne polarimetric Synthetic Aperture Radar. 3rd European Conference on Synthetic Aperture Radar, EUSAR 2000, 23-25 May, Munich, VDE Verlag, pp. 779-782.

Balzter, H., Baker, J. R., Tomppo, E., and Hallikainen, M., submitted, Retrieval of timber volume and snow water equivalent over a Finnish boreal forest from airborne polarimetric Synthetic Aperture Radar. International Journal of Remote Sensing,

Barkham, J., 1996, Nature conservation management of the Breckland flora. In Thetford Forest Park - The ecology of a pine forest, edited by P. Ratcliffe, and Claridge, J. (Edinburgh: Forestry Commission), pp. 33-43.

Bergen, K. M., Dobson, M. C., Pierce, L. E., and Ulaby, F. T., 1998, Characterizing carbon in a northern forest by using SIR-C/X-SAR imagery. Remote Sensing of Environment, 63, 24-39. Dawson, T., Luckman, A., and Balzter, H., 2000, Carbon offset verification in forest ecosystems. 28th International Symposium on Remote Sensing of Environment, 23-25 March, Cape Town, SA.

Ferris, R., Peace, A. J., Humphrey, J. W., and Broome, A. C., 2000, Relationships between vegetation, site type and stand structure in coniferous plantations in Britain. Forest Ecology and Management, 136, 35-51.

Forestry Commission, 1981, Yield models for forest management (booklet 48), (Edinburgh: Forestry Commission).

Fransson, J. E. S., and Israelsson, H., 1999, Estimation of stem volume in boreal forests using ERS-1 C- and JERS-1 L-band SAR data. International Journal of Remote Sensing, 20, 123137.

Hyyppä, J., Pulliainen, J., Hallikainen, M., and Saatsi, A., 1997, Radar-derived standwise forest inventory. IEEE Transactions On Geoscience and Remote Sensing, 35, 392-404. Imhoff, M. L., 1995, Radar Backscatter and Biomass Saturation - Ramifications For Global Biomass Inventory. IEEE Transactions On Geoscience and Remote Sensing, 33, 511-518. Imhoff, M. L., Sisk, T. D., Milne, A., Morgan, G., and Orr, T., 1997, Remotely sensed indicators of habitat heterogeneity: Use of synthetic aperture radar in mapping vegetation structure and bird habitat. Remote Sensing of Environment, 60, 217-227.

Israelsson, H., Ulander, L. M. H., Askne, J. I. H., Fransson, J. E. S., Frolind, P. O., Gustavsson, A., and Hellsten, H., 1997, Retrieval of forest stem volume using VHF SAR. IEEE Transactions On Geoscience and Remote Sensing, 35, 36-40.

Kurvonen, L., Pulliainen, J., and Hallikainen, M., 1999, Retrieval of biomass in boreal forests from multitemporal ERS-1 and JERS-1 SAR images. IEEE Transactions On Geoscience and Remote Sensing, 37, 198-205.

Luckman, A., Baker, J., Honzak, M., and Lucas, R., 1998, Tropical forest biomass density estimation using JERS-1 SAR: Seasonal variation, confidence limits, and application to image mosaics. Remote Sensing of Environment, 63, 126-139.

Plummer, S. E., 2000, Perspectives on combining ecological process models and remotely sensed data. Ecological Modelling, 129, 169-186.

Pulliainen, J. T., Mikkela, P. J., Hallikainen, M. T., and Ikonen, J. P., 1996, Seasonal dynamics of C-band backscatter of boreal forests with applications to biomass and soil moisture estimation. IEEE Transactions On Geoscience and Remote Sensing, 34, 758-770. 
Randall, R., and Dymond, D., 1996, Why Thetford forest? The human and natural history of Breckland before the early 20th century. In Thetford Forest Park - The ecology of a pine forest, edited by P. Ratcliffe, and Claridge, J. (Edinburgh: Forestry Commission), pp. 1-15. Ranson, K. J., and Sun, G. Q., 1997, An evaluation of AIRSAR and SIR-C/X-SAR images for mapping northern forest attributes in Maine, USA. Remote Sensing of Environment, 59, 203222.

Schmullius, C. C., and Rosenqvist, A., 1997, Closing the Gap - a Siberian Boreal Forest Map with ERS-1/2 and JERS-1. 3rd ERS Symposium on Space at the Service of our Environment, Florence, Italy, ESA, pp. 1885-1890. 


\section{Tables}

Table 1: Metadata of the L-band HH polarised SAR imagery. All images were resampled to $12.5 \mathrm{~m}$ pixel spacing.

\begin{tabular}{llccc}
\hline satellite & scene & $\begin{array}{c}\text { acquisition } \\
\text { date }\end{array}$ & $\begin{array}{c}\text { number of } \\
\text { looks }\end{array}$ & incidence angle $\left[{ }^{\circ}\right]$ \\
\hline SEASAT & orbit 762, scene & $19 / 08 / 1978$ & 4 & 20 \\
& SE207 & & 3 & 35 \\
\hline
\end{tabular}




\section{Figure captions}

Figure 1: Parameters of the vegetation canopy model. The canopy is a collections of three basic cylinders representing stems $(s)$, branches $(b)$ and needles $(n)$. The curves show the variation on a logarithmic scale of the number density per $\mathrm{m}^{3}(n d)$, length in $\mathrm{m}(l)$ and radius in $\mathrm{m}(r)$ of the vegetation components at increasing canopy height $h$. Stems are upright, branches and needles have spherical inclination angles and uniform $\left(-180^{\circ}\right.$ to $\left.+180^{\circ}\right)$ orientation angles. Temperature is set to $22^{\circ} \mathrm{C}$, gravimetric moisture of the cylinders to 0.6; the soil is modelled using a small perturbation model, and a ground susceptibility model by Hallikainen (1985) assuming a volumetric moisture content of 0.2 , and a composition of $50 \%$ sand, $25 \%$ clay and $25 \%$ silt.

Figure 2: Modelled L-HH backscatter coefficient for increasing tree height, simulated by RT2 using the cylinder model for the vegetation layer as described in the text. Also shown are the contributions by the ground, layer and layer-ground interactions.

Figure 3: Change detection from multitemporal L-band SAR at Thetford forest (British National Grid coordinates). Red: backscatter change, green: JERS-1 backscatter coefficient (1997), blue: SEASAT backscatter coefficient (1978). Yellow areas indicate forest regrowth, dark blue areas are clearcuts, light blue is undisturbed forest, and brown areas are agricultural fields.

Figure 4: Backscatter coefficient $\sigma^{0}$ from SEASAT and JERS-1 vs. mean top height $h[\mathrm{~m}]$ of Corsican Pine stands derived from general yield class curves (minimum stand size 10 pixels).

Figure 5: Direct method of retrieving tree growth from backscatter change, showing the three fitted models (red $=$ square root, green $=$ linear, blue $=\log$ model). $s_{l o g}$ and $s_{\text {sqrt }}$ indicate the saturation limits of the logarithmic and the square root model.

Figure 6: Tree growth of Corsican Pine estimated by the direct method with the linear model $\left(\Delta h_{d i r}\right)$ and the indirect method $\left(\Delta h_{\text {ind }}\right)$ compared to expected growth $\left(\Delta h_{F C}\right)$ from the Forestry Commission's general yield class model. The $45^{\circ}$ line is shown in red.

Figure 7: Dependence of rmse of $\Delta h$ estimates from SAR on mimimum stand area $a_{\text {min }}$. rmse decreases when only larger forest stands are included in the analysis.

Figure 8: rmse of $\Delta h$ estimates by the direct (linear model) and the indirect method for all forest stands and for stands with areal extent of $>2.1$ ha.

Figure 9: Map of tree growth $\Delta h_{\text {dir }}[\mathrm{m}]$ between 1978 and 1997 at Thetford forest estimated by the direct method and linear model. Each class represents a 10\%-quantile. British National Grid Coordinates are shown.- 
Figures

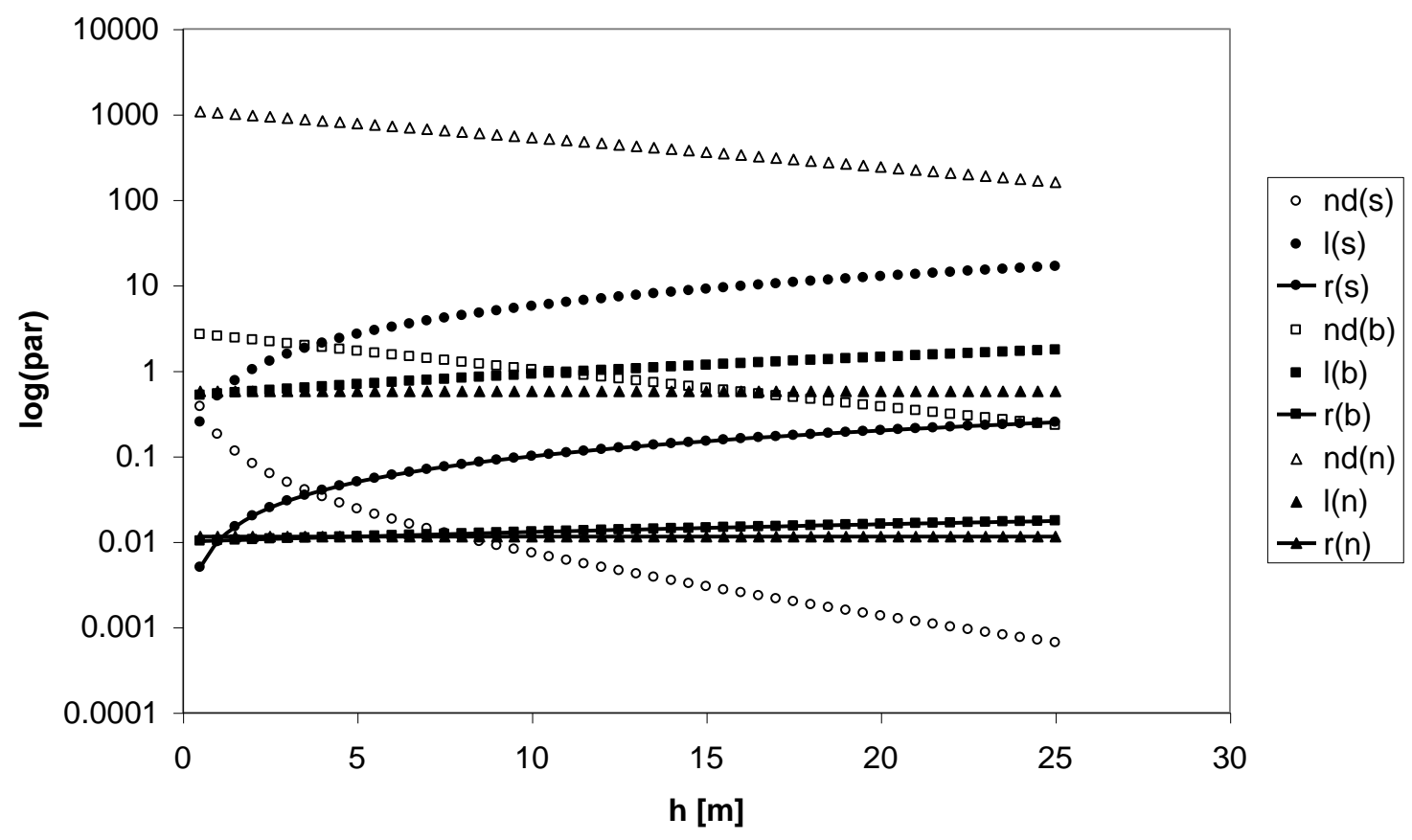

Fig.1 


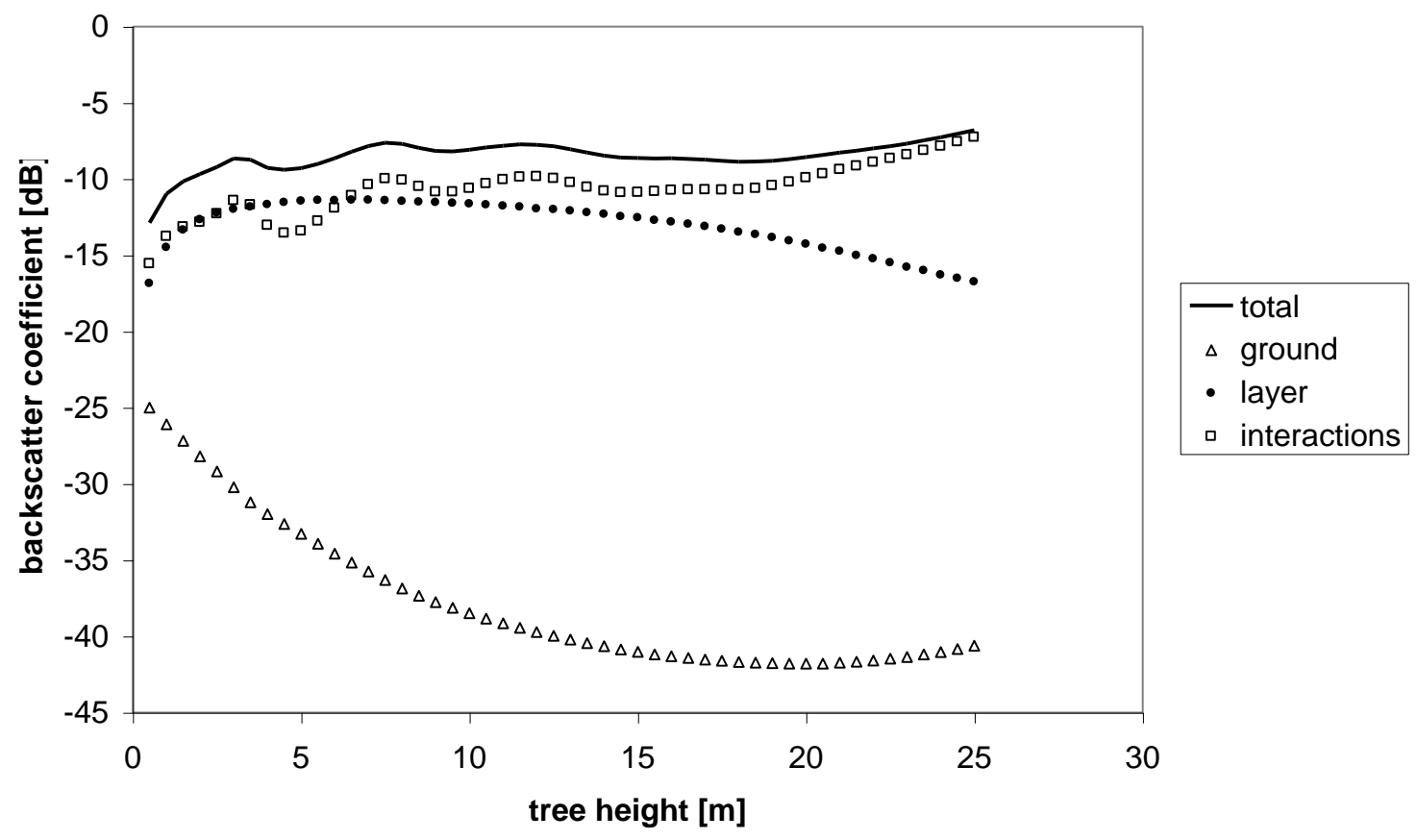

Fig. 2 


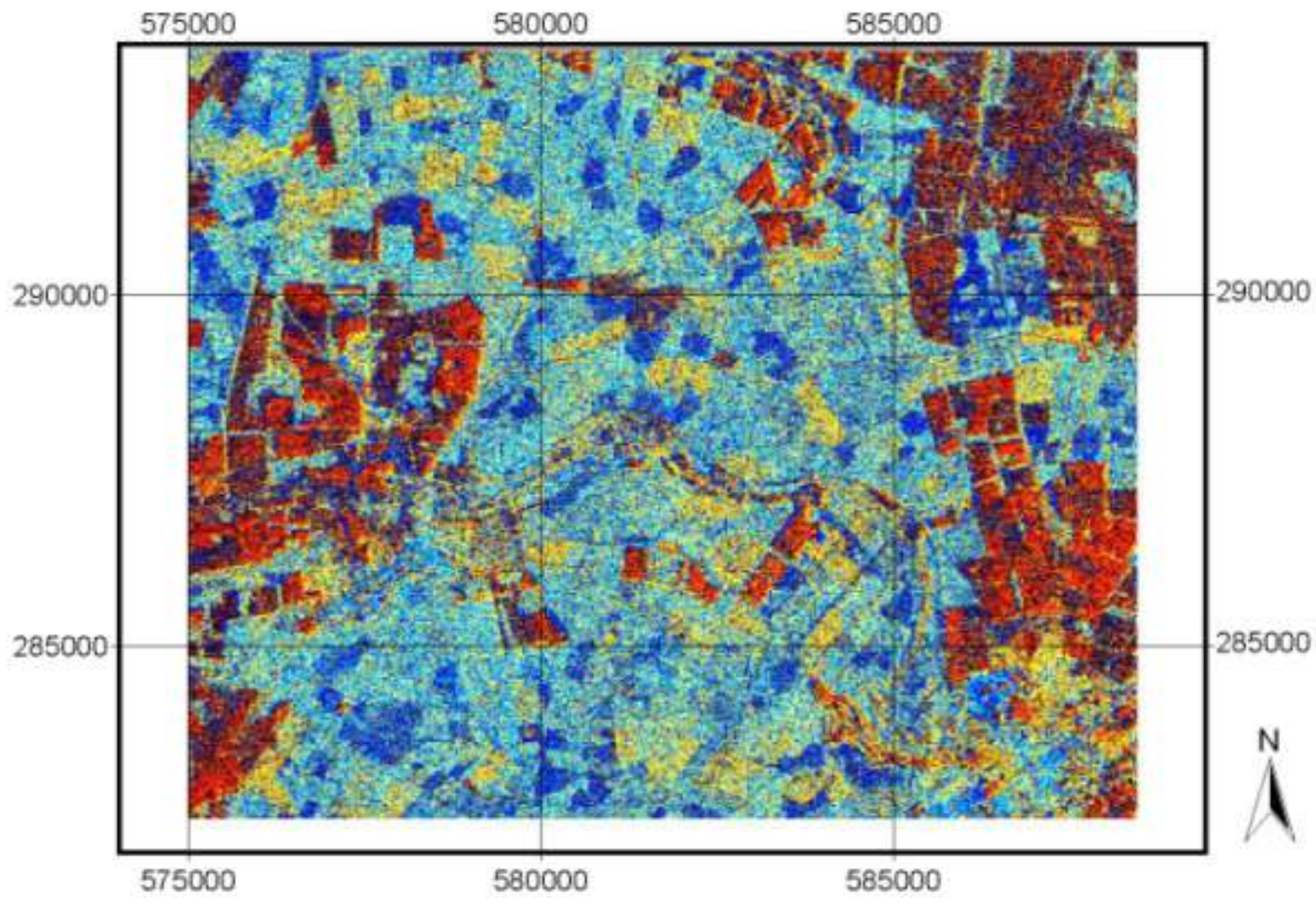

Fig. 3 


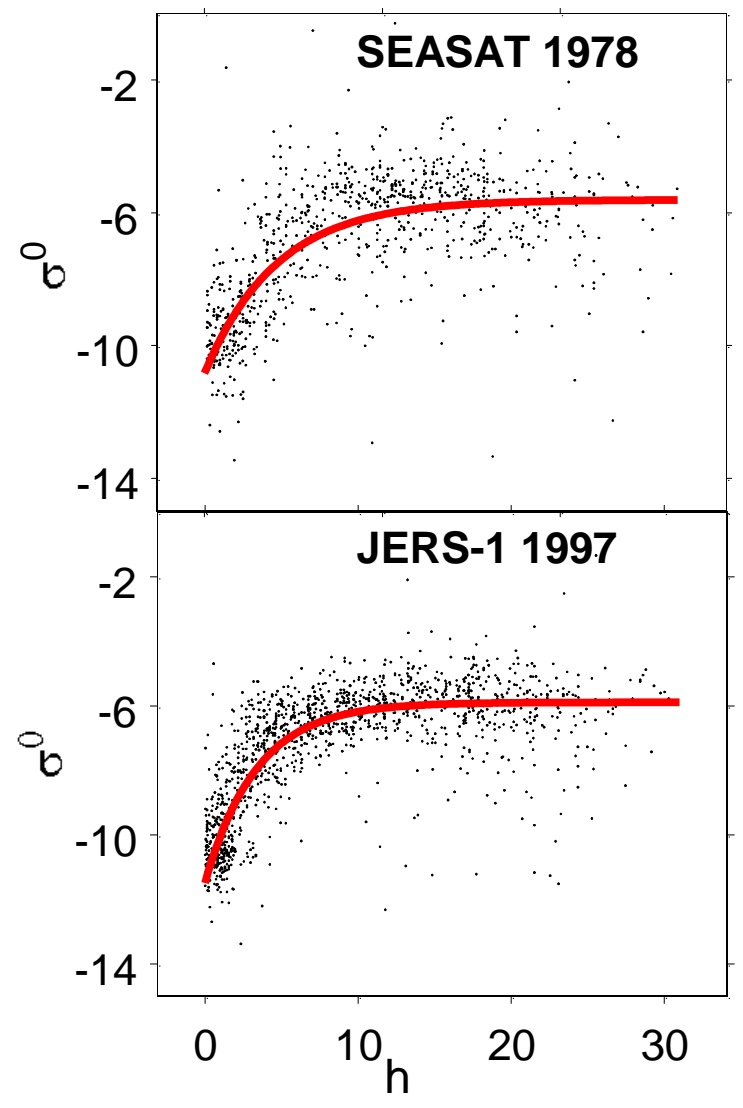

Fig. 4 


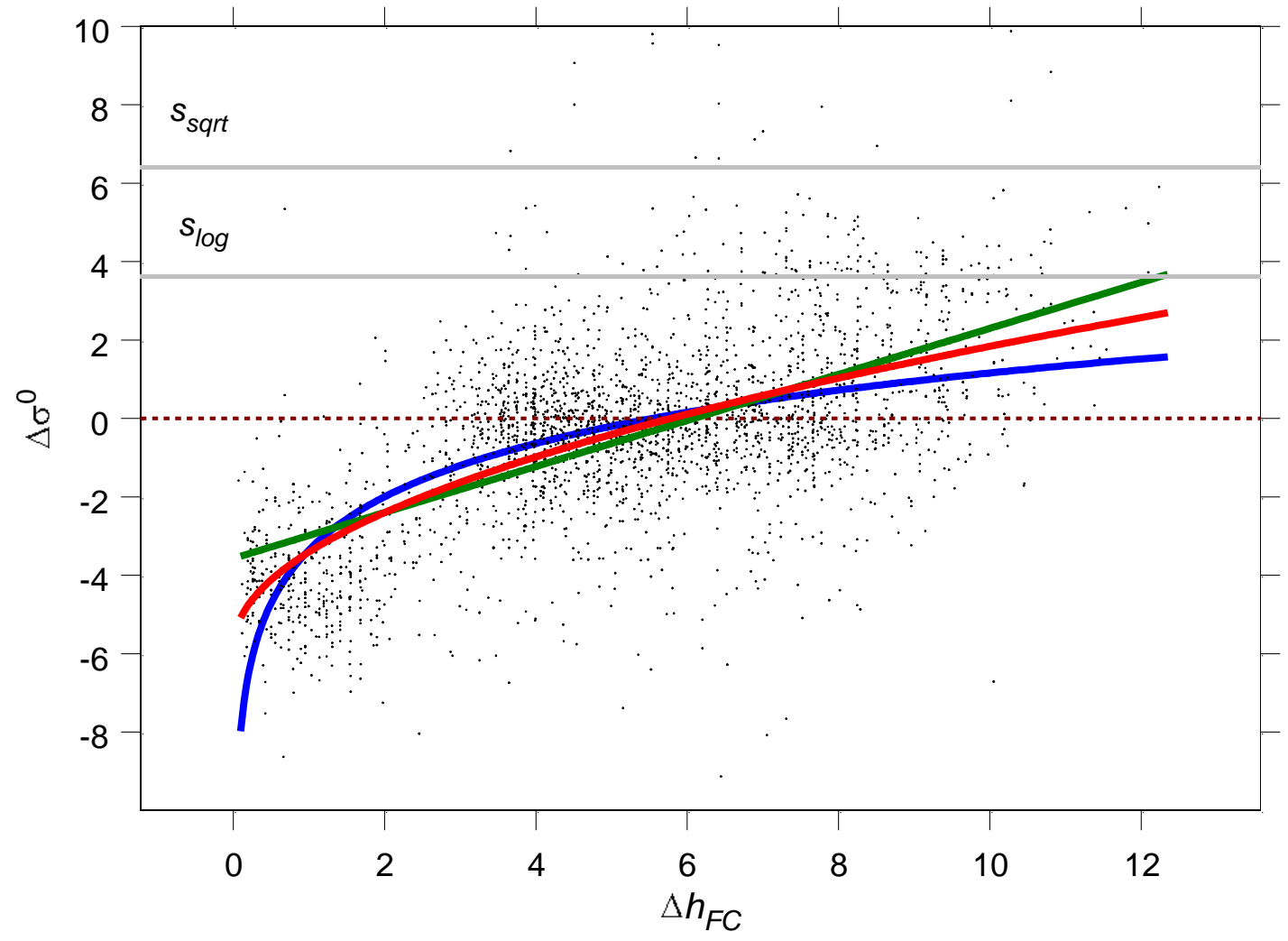

Fig. 5 

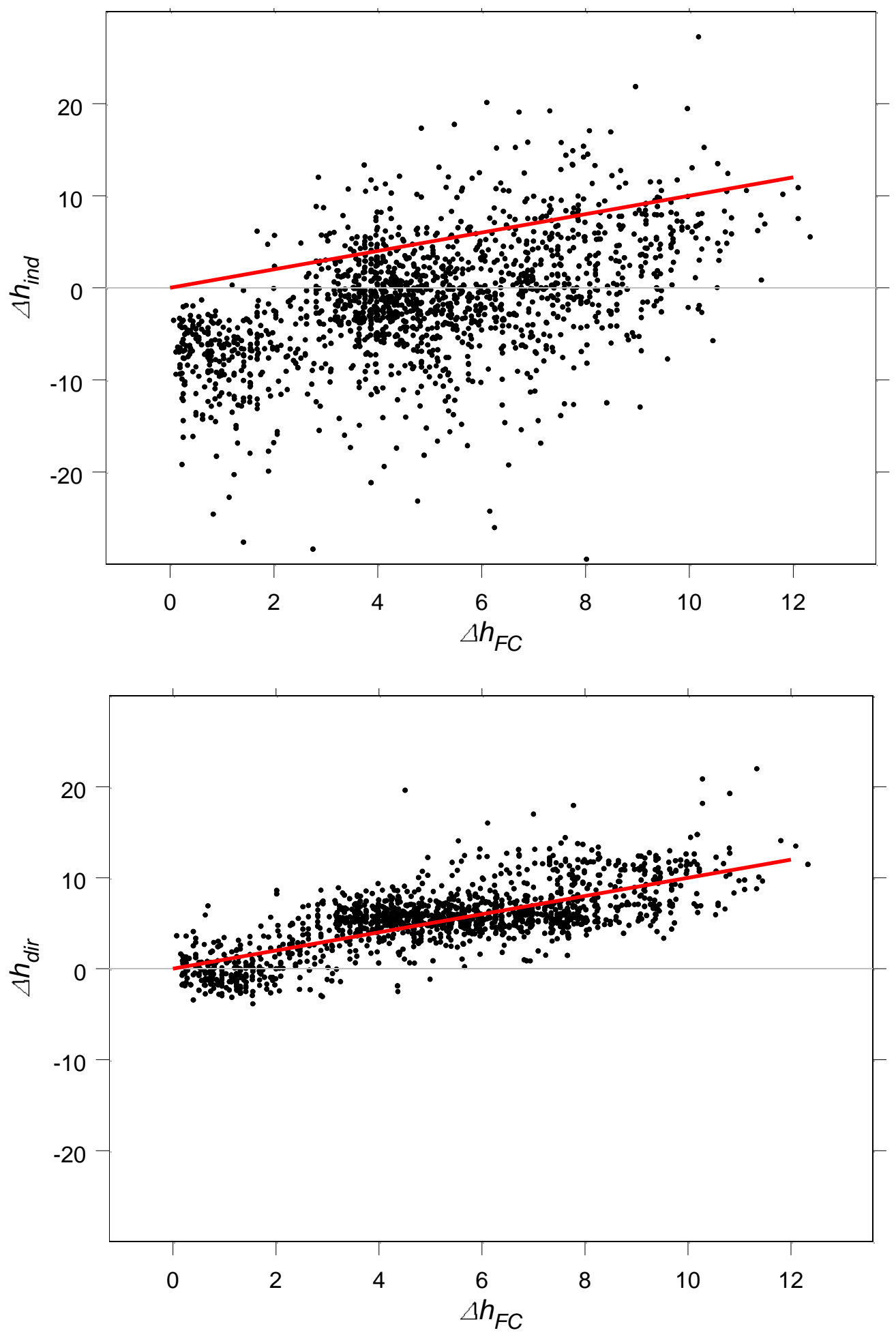

Fig. 6 


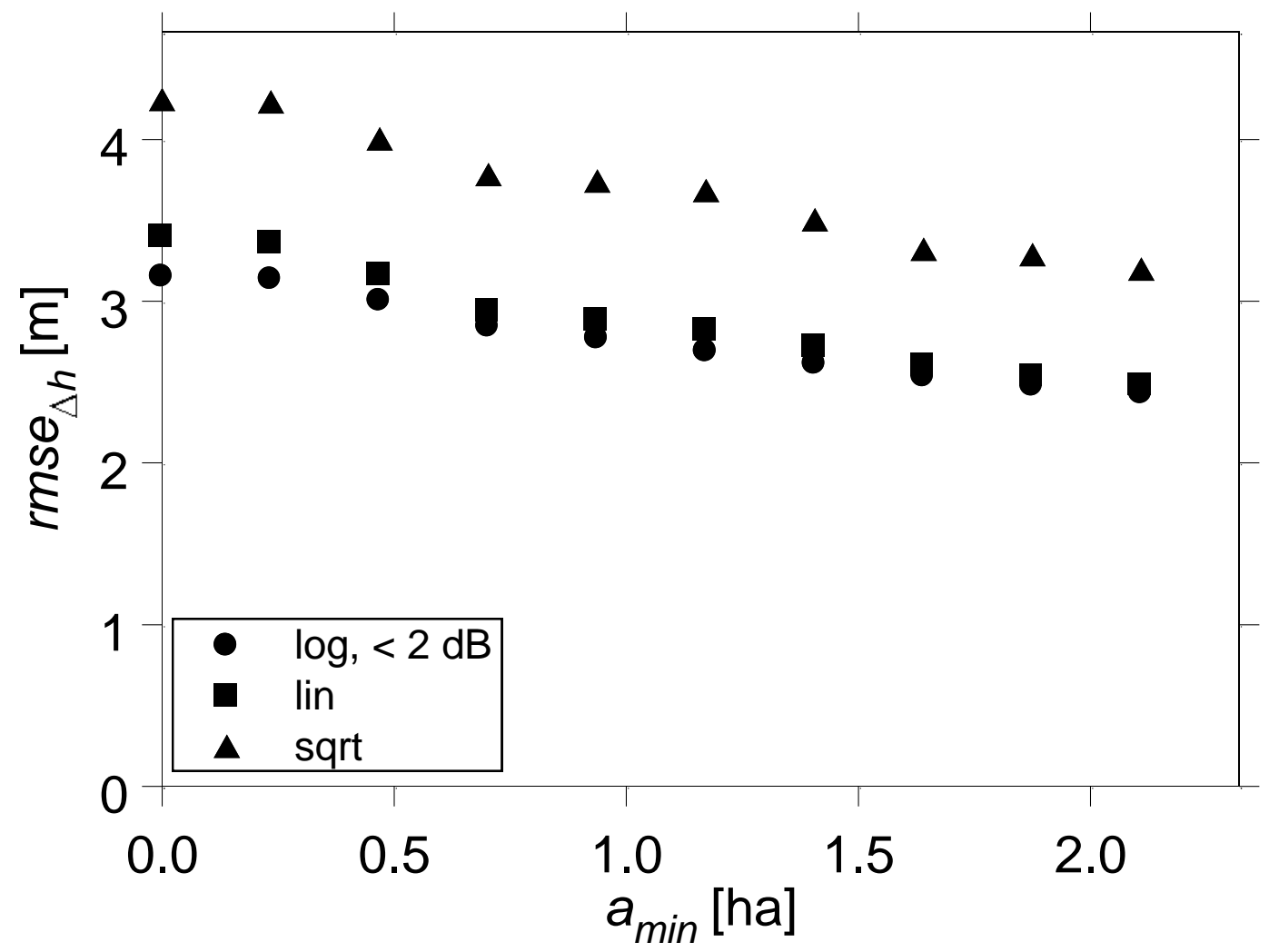

Fig. 7 


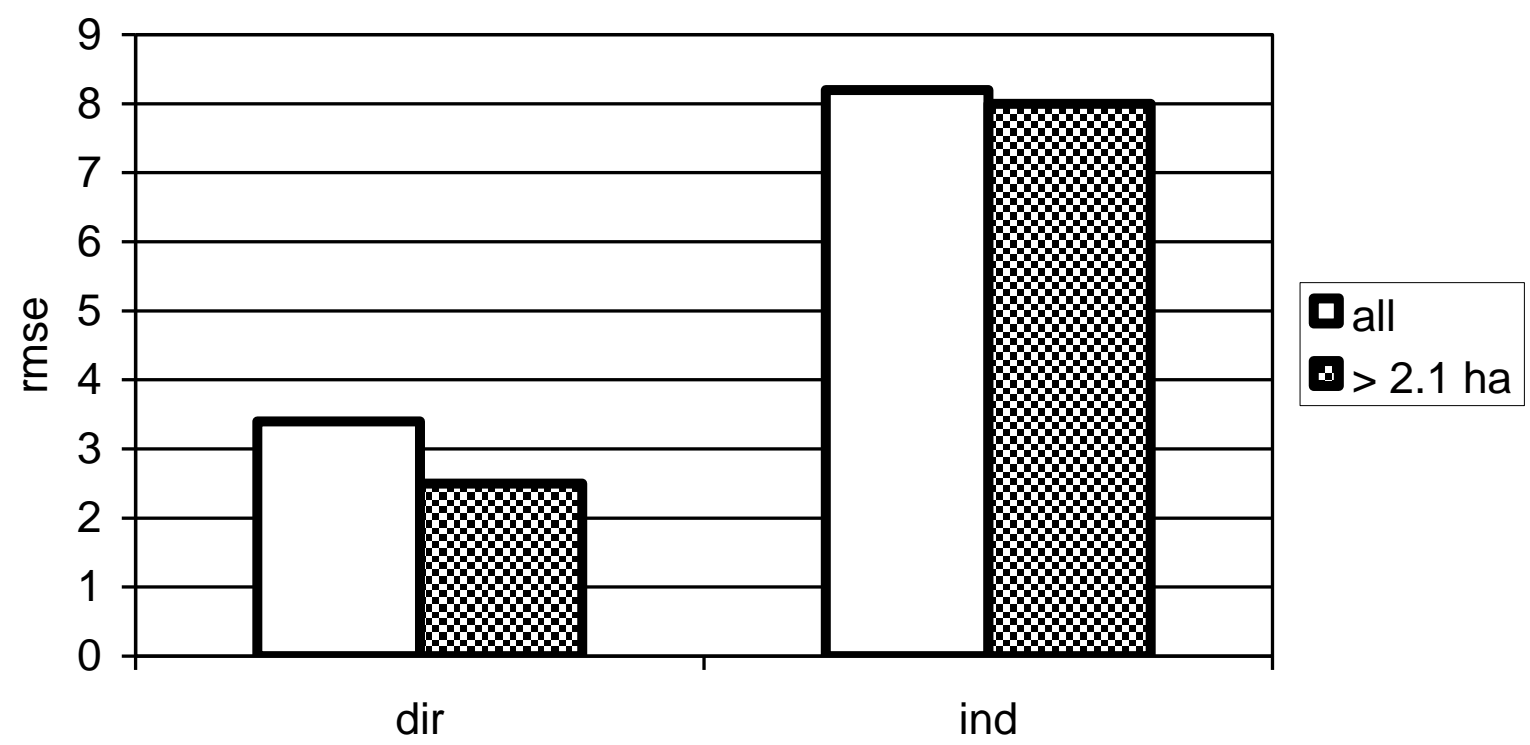

Fig. 8 


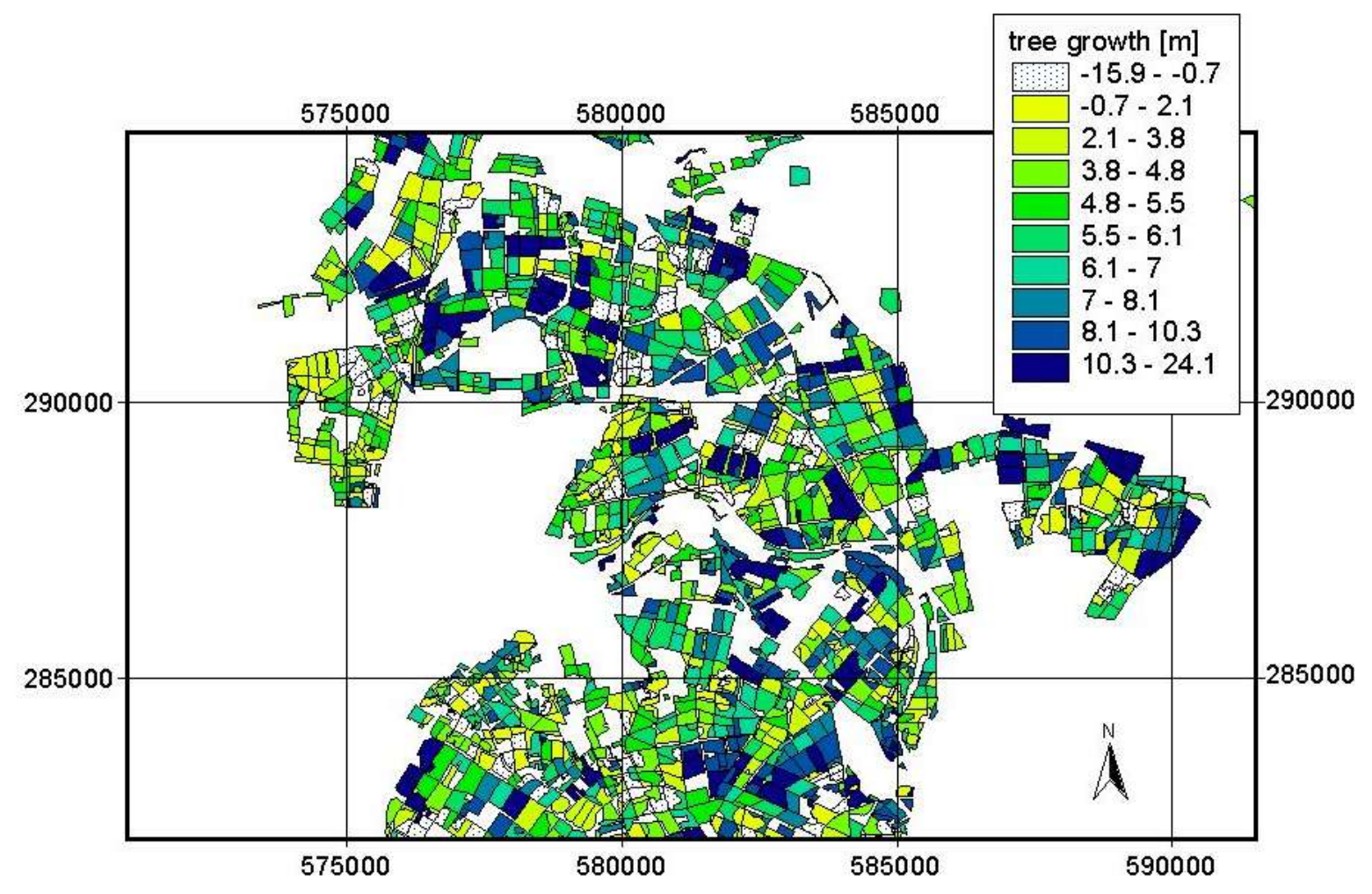

Fig. 9 